\title{
End-to-side versus end-to-end neurorrhaphy at the peroneal nerve in rats ${ }^{1}$
}

Fausto Viterbo', Ryane Schmidt Brock", Fábio Maciel"', Benoit Ayestaray ${ }^{\mathrm{IV}}$, José Antonio Garbinov, Cecília Pessoa Rodrigues ${ }^{\mathrm{VI}}$

'PhD, Associated Professor, Division of Plastic Surgery, Universidade Estadual Paulista (UNESP), Botucatu-SP, Brazil. Conception, design, intellectual and scientific content of the study; critical revision.

"MsC, PhD, Plastic Surgeon, Sociedade Brasileira de Cirurgia Plástica, Sao Paulo-SP, Brazil. Aquisition of data, manuscript writing.

I'Assistant Professor, Physiotherapy, Institute for Health and Biotechnology, Universidade Federal do Amazonas (UFAM), Coari-AM, Brazil. Scientific content of the study, acquisition of data, manuscript writing.

IVAssistant Professor, Department of Plastic and Reconstructrive Surgery, Sud Francilien Hospital, University Paris, Corbeil-Essonnes, France. Aquisition of data.

VPhD of Science, Specialist in Clinical Neurophysiology and Medical Rehabilitation, Section Head of Assessment and Diagnosis, Instituto Lauro de Souza Lima, Bauru-SP, Brazil. Intellectual and scientific content of the study, critical revision.

V'Graduate student, Biomedicine Course, UNESP, Botucatu-SP, Brazil. Aquisition of data.

\begin{abstract}
Purpose: To evaluate three different kinds of neurorrhaphy of the peroneal nerve.

Methods: Eigthy rats were divided into 5 groups. Control: nerve had no intervention. End-toend $(E E)$ : nerve was cut and elongated with a nerve graft with two end-to-end neurorrhaphies. End-to-side (ES): nerve was cut and sutured to the graft with at the lateral side of the nerve. Side-to-end (SE): the nerve was cut and sutured to the graft with end-to-end neurorrhaphy. Denervated: nerve was cut and both endings were buried into the muscle. The evaluation was done by walking track analysis, electrophysiology, body mass, cranial tibial muscle mass, nerve and muscle fibers morphometry.

Results: The EE, ES and SE have the same potential of reinnervation.

Conclusion: There is no functional or histological difference between these different types of neurorrhaphy.

Key words: Peroneal Nerve. Nerve Regeneration. Peripheral Nerves. Microsurgery. Rats.
\end{abstract}




\section{Introduction}

Peripheral nerve can have inflammatory, traumatic, metabolic, toxic, genetic and neoplastic diseases, which develops different types and grades of nerve lesions. To repair peripheral nerve injuries the end-toend neurorrhaphy (EE) is frequently used connecting the proximal to the distal ending. However, the proximal end of the nerve may be lost sometimes or not available. One of the solutions is to use a neighbouring nerve as donor, but this leads to a functional deficiency to the innervated structures ${ }^{1}$.

A choice to avoid donor nerve morbidity is the side-to-end (SE) or end-toside (ES) neurorrhaphy proposed by Viterbo et $a .^{2-4}$. These authors demonstrated the reinnervation of the cranial tibial muscle in rats after a suture between the distal ends of the peroneal nerve to the lateral side of the tibial nerve. Viterbo et al. also compared in the same experimental model SE with and without epi-perineurium window. The results in reinnervation demonstrated no significant morphological or electrophysiological differences ${ }^{5}$. Ballance et al. ${ }^{6}$ proposed a similar end-to-side neurrorhaphy with the distal end of the facial nerve to the lateral side of the spinal accessory nerve, but the facial movements were simultaneous to the shoulder. Other authors also used this technique; however, all of them did a partial incision at the donor nerve, connecting endoneural tubes between donor and receptor nerves in an end-to-end model. However, harming the donor nerve led to functional problems ${ }^{6-11}$.

The absence of functional deficiency in the donor nerve with the end-to-side neurorrhaphy makes any nerve a potential donor one. This fact allows new treatment possibilities to several differentnerve injurie ${ }^{12-16}$. The axonal lateral sprouting occurs after the absortion of the three-conjuntival layers: epineurium, perineurium and endoneurium ${ }^{17}$.
The mechanism of this absortion and axonal lateral sprouting is still unknow. Some authors demonstrated that nerve growth factors and other substances are probably involved ${ }^{18}$. Although many authors believe the ES or SE neurrorhaphies are good procedures, they only use them in difficult cases, where no other options could be used. It is almost a consensus that the EE is superior to both ES or $\mathrm{SE}^{18,19}$. Some experimental studies found superiority of the EE compared to the ES or SE, but they used different donor nerves ${ }^{18,19}$. The objective of this study is to compare end-to-side, sideto-end and end-to-end neurorrhaphies of the peroneal nerve in rats with the same donor nerve, the peroneal nerve.

\section{Methods}

The study was previously aproved by the Animal Ethics Comittee of Universidade Estadual Paulista.

Eighty male Wistar rats with a mean weight of $283.44 \mathrm{~g}(+/-34.03)$ were used. All animals were provided by the Central Animal Laboratory of the Paulista State University (UNESP), at Botucatu Campus and were randomized into 5 groups.

The animals had their body mass measured and submited to intramuscular anaesthesia with Xylasine (Anasedan ${ }^{\circ}$ ) $30 \mathrm{mg} /$ $\mathrm{Kg}$ and Ketamine $70 \mathrm{mg} / \mathrm{Kg}$. The lateral dorsum of one posterior member, rigth or left, had a 2.5 $\mathrm{cm}$ longitudinal skin incision. The side depended on blind randomization. The peroneal nerve was dissected through a posterior muscle divulsion. The same procedure was used in all experimental groups. Two plastic surgeons trained on microsurgery did the procedures.

Control group (CG) (10 animals): The peroneal nerve was dissected without nerve section or neurorrhaphy.

Denervation group (DG) (10 animals): The peroneal nerve was sectioned, the distal 
end was turned 180 degrees and fixed into the adjacent muscle. The proximal end was transpassed through the gluteous muscle and fixed outside to avoid motor nerve contamination.

End-to-end group (EE) (20 animals): peroneal nerve was cut and repaired with endto-end neurorrhaphy with an interposition of a $1 \mathrm{~cm}$ sural nerve graft.

End-to-side group (ES) (20 animals): The peroneal nerve was seccioned and the proximal end was sutured to a $1 \mathrm{~cm}$ sural nerve graft. The distal end was buried into an adjacent muscle and the nerve graft was sutured the lateral side of the distal peroneal nerve $0,5 \mathrm{~cm}$ distant from its extremity with two stitches of a 10.0 mononylon suture.

Side-to-end group (SE) (20 animals): The peroneal nerve was sectioned, a $1 \mathrm{~cm}$ sural nerve graft was sutured at the proximal end and the distal graft end was fixed into the adjacent muscle. The distal peroneal end was sutured to the lateral side of the nerve graft distant 0.5 $\mathrm{cm}$ from its extremety. Neurorrhaphies were done without epineural resection (Figure 1). All sutures used two stitches of a 10.0 mononylon suture.

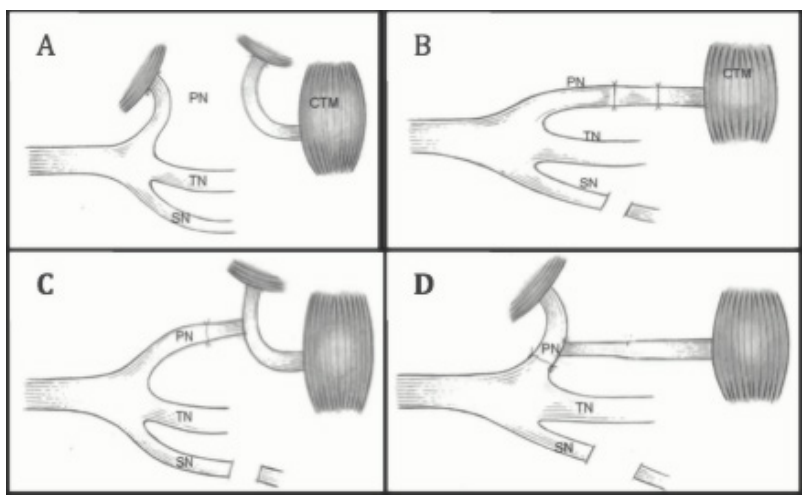

Figure 1 - A: Denervated group (DG). B: End-to-end neurorrhaphy (EE). C: End-to-side group (ES). D: Side-to-end group (SE). (PN - Peroneal Nerve, TN Tibial Nerve, SN - Sural Nerve, CTM - Cranial Tibial Muscle).
The surgeries were performed with the surgical microscope MU-M19 DF Vasconcelos (Sao Paulo-SP) with magnification of 10 and 16 times. At the end of the procedure, skin and subcutaneous tissue were sutured with mononylon 5.0. Animals were maintained in appropriate cages (five rats by cage) in the Technique and Experimental Surgery Laboratory, Surgery and Orthopedic Department, UNESP, with 24 으 temperature $( \pm 0.5 \circ \mathrm{C})$, water and food ad libitum and a $12 \mathrm{~h}$ day/night cycle.

\section{Walking track analysis}

A physician did walking track analysis in a blinded manner at 90 and 180 days post operative. Previously trained animals walked in a $9 \mathrm{~cm}$ wide by $78 \mathrm{~cm}$ long chute with their floor covered with a strip of appropriately sized white paper after their hind feet were painted with black ink to mark the paper footprint. The footprints marked on the sheet of paper were analyzed by the measures of Normal Toes Spread (NTS); Experimental Toes Spread (ETS); Normal Print Length (NPL) and Experimental Print Length (EPL). It was used a functional index of the peroneal nerve according to Bain et $a .^{20,21}$.

\section{Electrophysiological test}

For electrophysiological testing, the temperature was maintained around $25^{\circ} \mathrm{C}$. The compound action potential was recorded by needle electrodes active and reference. The reference electrode was placed in rats cranial tibial muscle tendon, the active electrode in cranial tibial muscle belly, and the dispersive electrode, introduced in a location away from the test region. The electrodes recorded the amplitude and latency of the muscle action potential. The pulses were generated by a bipolar electrode, whose cathode and anode were $2 \mathrm{~mm}$ apart, which was positioned directly over the sciatic nerve prior to neurorrhaphy 
region, and the stimulation was made proximal to the neurorrhaphy, enabling the spread of electrical impulses through them. The frequency of the stimulus was set at 1 pps and $100 \mathrm{~ms}$ in duration. The stimulus intensity used, constant in all animals was 5.1 volts. The Electrophysiology apparatus used was the Sapphire II 4ME.

\section{Histological analysis}

After 180 post operative days, animals were submited to anaesthesia as described previously and after the eletrophisiological study, the animals were sacrificed with letal doses of pentobarbital sodium intraperitoneal. The body mass and the cranial tibial mass were measured using a balance. Nerves and muscles were ressected and histologically prepared to mophometric studies. Physicians did not know the type of neurorrhapy performed previously for each rat.

Nerve fragments were fixed in Karnovisk and posterior osmium tetroxide $1 \%$. They were dehydrated in acetone (50\%, 70\%, 90\% and $100 \%$ ) in Araldite 502 . Transversal cuts were done at the distal part of the peroneal nerve with 0.3 microns and stained with toluidine blue $0.25 \%$. The transversal nerve fragment was submited to a transectional fiber number analysis, nerve area and diameter with optical microscopy. Longitudinal analysis was also done to analyse the fiber and the lateral axonal sprouting positions. The digital images were studied with Sigma Pro Image Analysis 5.0 software from Jardel Scientific Corporation (San Jose, CA).

Cranial tibial muscles were removed. The mass was measured and fixed in liquid nitrogen. Histological segments were prepared in a LEICA - CM 1800 cryostat at negative $20^{\circ} \mathrm{C}$, with 7 micra in transversal direction and tha diameter at the central portion of the muscle. It was stained with hematoxylin-eosin. The minimal diameter and area was simultaneously measured and the images were analysed with
Sigma Pro Image Analysis 5.0 software by Jardel Scientific Corporation (San Jose, CA).

\section{Statistical analysis}

The Groups were compared by analysis of variance. When this analysis detected significant difference, the Tukey test was used to multiple comparision of means. When the normality test failed, it was used the KruskalWalis followed by the Dunn's method. Statistical significance was defined as $p \leq 0.05$. The program used for the analysis was SigmaStat 3.5 Software Jandel Scientific Corporation (San Jose, CA).

\section{- Results}

Animals had similar initial and final body mass, with no statistical difference at variance analysis of the groups (Control, EE, $E S, S E$, Denervated) (initial mass: $p=0.542$ and final mass: $p=0.086)$. The cranial tibial muscle mass was measured and analysed by Kruskal-Wallis test. It demonstrated a higher mass in the control group and similar results in EE, ES and SE groups. The denervated group demonstrated lower muscle mass $(p<0.001)$. The latency analysis did not find statistical difference between groups according to nonparametric analysis (Kruskal-Wallis) $(p=0.113)$. Parametric analysis of amplitude variance with Tukey test demonstrated statistical higher values in control group compared to EE and denervated groups. There was no statistical significant difference between the ES and SE groups $(p<0.006)$. Non-parametric analysis (Kruskal-Wallis test) of the functional peroneal index (FPI) at 90 days demonstrated lower values in the denervated group compared to the others groups $(p<0.004)$. The variance analysis of the functional peroneal index (FPI) at 180 days demonstrated also lower results in the denervated group and similar results in the others groups $(p<0.001)$ (Table 1$)$. 
Table 1 - All morphometric, eletrophisiological study and functional results.

\begin{tabular}{|c|c|c|c|c|c|c|}
\hline & Control & EE & ES & SE & Denervated & $\mathbf{p}$ \\
\hline TCM mass $(\mathrm{g})^{*}$ & $0.99 \pm 0.1 a$ & $0.67 \pm 0.18 b$ & $0.65 \pm 0.14 b$ & $0.68 \pm 0.16 b$ & $0.21 \pm 0.11 c$ & $<0.001$ \\
\hline Latency $(\mathrm{ms})^{*}$ & $2.03 \pm 0.23$ & $1.95 \pm 0.32$ & $2.08 \pm 0.47$ & $2.32 \pm 0.43$ & $3.48 \pm 3.48$ & $=0.113$ \\
\hline Amplitude (mV)\# & $21.64 \pm 10.74 a$ & $11.02 \pm 7.79 b$ & $14.66 \pm 8.57 a b$ & $\begin{array}{l}14.47 \pm \\
8.07 a b\end{array}$ & $8.53 \pm 5.45 b$ & $<0.006$ \\
\hline FPI 90 days* & $-17.65 \pm 4.84 a$ & $-23.92 \pm 35.53 a$ & $\begin{array}{l}-23.46 \pm \\
34.37 a\end{array}$ & $\begin{array}{l}-28.12 \pm \\
40.22 a\end{array}$ & $\begin{array}{l}-93.02 \pm \\
51.83 b\end{array}$ & $<0.004$ \\
\hline FPI 180 days\# & $-14.27 \pm 5.22 a$ & $-19.25 \pm 39.62 a$ & $-34.89 \pm 34.4 a$ & $-15.0 \pm 30.41 a$ & $\begin{array}{l}-129.34 \pm \\
49.26 b\end{array}$ & $<0.001$ \\
\hline NFN\# & $\begin{array}{l}2205.75 \pm \\
289.34\end{array}$ & $\begin{array}{l}1867.0 \pm \\
441.51\end{array}$ & $\begin{array}{l}1810.25 \pm \\
406.11\end{array}$ & $\begin{array}{l}1609.25 \pm \\
278.74\end{array}$ & - & $=0.194$ \\
\hline $\operatorname{MST}(\mu \mathrm{m})^{*}$ & $3.76 \pm 1.68 a$ & $2.29 \pm 0.46 a b$ & $2.45 \pm 0.85 a b$ & $2.15 \pm 0.34 b$ & - & $<0.05$ \\
\hline $\operatorname{MSA}\left(\mu \mathrm{m}^{2}\right) \#$ & $44.36 \pm 26.93 a$ & $18.54 \pm 8.19 b$ & $23.62 \pm 11.11 b$ & $16.08 \pm 5.11 b$ & - & $<0.05$ \\
\hline $\operatorname{NFMD}(\mu \mathrm{m}) \#$ & $7.84 \pm 2.22 a$ & $5.1 \pm 1.17 b$ & $5.66 \pm 1.23 b$ & $4.61 \pm 0.81 b$ & - & $<0.05$ \\
\hline $\operatorname{NFTA}\left(\mu m^{2}\right) \#$ & $63.4 \pm 30.5 a$ & $29.06 \pm 11.83 b$ & $37.74 \pm 14.29 b$ & $25.13 \pm 8.24 b$ & - & $=0.05$ \\
\hline TCM FA $\left(\mu \mathrm{m}^{2}\right)^{*}$ & $\begin{array}{l}2716.54 \pm \\
1544.51 a\end{array}$ & $\begin{array}{l}2480.59 \pm \\
12.99 a\end{array}$ & $\begin{array}{l}3278.13 \pm \\
1825.33^{\text {a }}\end{array}$ & $\begin{array}{l}2898.38 \pm \\
1006.22 \mathrm{a}\end{array}$ & $\begin{array}{l}960.59 \pm \\
633.85 b\end{array}$ & $<0.001$ \\
\hline MFMD $(\mu \mathrm{m}) \#$ & $45.55 \pm 12.26 a$ & $45.47 \pm 8.84 a$ & $48.14 \pm 13.9 a$ & $49.09 \pm 9.57 a$ & $25.5 \pm 9.43 b$ & $<0.001$ \\
\hline
\end{tabular}

*Kruskal-Wallis Dunn'S Method; \# ANOVA Tukey Test; Tibial Cranial Muscle mass = TCM mass; Nerve fiber number = NFN; Myelin sheath thickness = MST; Myelin sheath area = MSA; Nerve fiber Minimum diameter = NFMD; Nerve fiber transversal area = NFTA; Tibial Cranial Muscle Fibers Area = TCMFA; Muscle fiber minimum diameter = MFMD. EE: End-to-end group. ES: End-to-side group. SE: Side-to-end group. TCM: tibial cranial muscle. FPI: functional peroneal index.

The analysis of variance of the nerve fiber number demonstrated no statistical difference between groups $(p=0.194)$. The myelin sheath thickness analysis demonstrated statistically higher values in the control group compared to SEG $(p=0.015)$, however, there were no statistically difference between the control group, EE and ES groups ( $p>0.05$ ) (Table 1 ). The analysis of variance of the myelin sheat area showed higher values in the control group compared to SE $(p=0.008), E E(p=0.022)$ and ES $(p=0.038)$ groups and there was no statistically difference between ES, SE and EE ( $p>0.05)$ (Table 1).

The minimum diameter of the nerve fiber analysis demonstrated statistically higher values in the control group than in the ES $(p=0.001), E E(p=0.01)$ and $S E(p=0.02)$ groups.
The ES, SE and EE groups had no statistically significant difference in the minimum diameter values $(p>0.05)$ (Table 1$)$. The analysis of variance of the nerve fiber area demonstrated statistically higher values in the control group than in the other groups, however the comparison of ES, SE and EE demonstrated no statistically significant difference in the nerve fiber area values $(p=0.05)$ (Table 1$)$.

Non-parametric analysis of the muscle fibers area $\left(\mu \mathrm{m}^{2}\right)$ did not demonstrate statistically significant difference between control, EE, ES and SE groups, but demonstrated lower values in the denervated group $(p<0.05)$ (Table 1).

The analysis of variance of the muscle fiber minimum diameter $(\mu \mathrm{m})$ also demonstrated similar statistical values in the 
control, EE, ES and SE groups, but demonstrated lower values in the denervated group $(p<0.001)$. During histological preparations, some technical problems occurred with the resin used in the denervated group. For this reason, this group was not included in the histological study.

Morphological results of all transversal nerve fragment submitted to nerve fiber number analysis, in area and diameter, at an optical microscope demonstrated no significant difference in the control, EE, ES and SE groups (Figure 2).

Morphological results of the tibial cranial muscle submited to area analysis showed no significant difference in the control, $E E, E S$ and SE groups, but significantly lower and smaller muscle fibers in the denervated group (Figure 3).

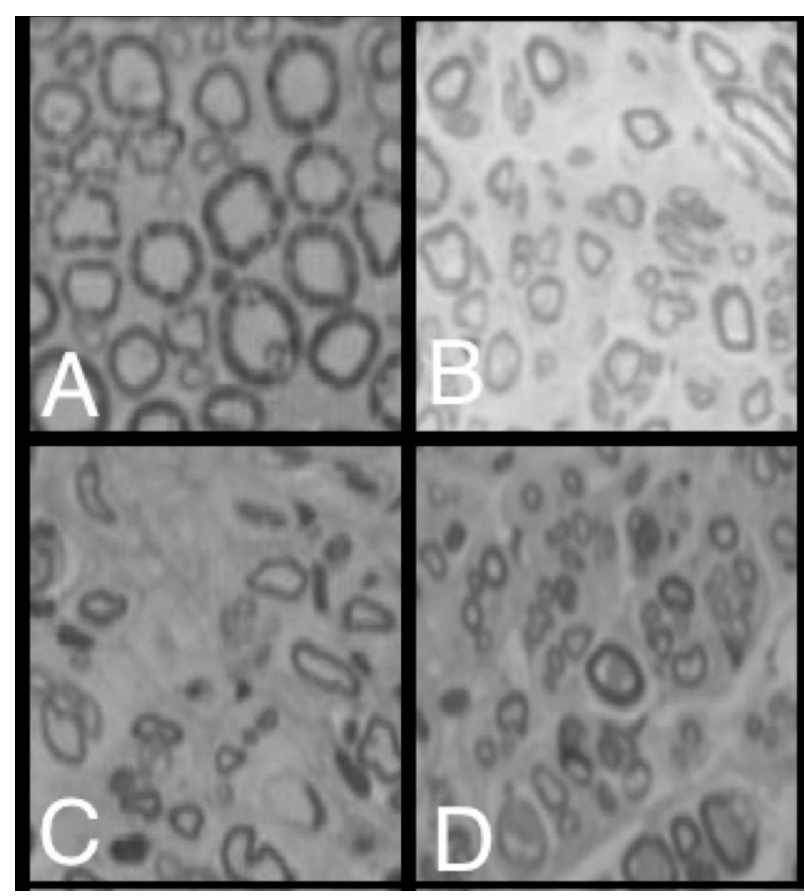

Figure 2 - Distal segment of the peroneal nerve. A: control group. B: EE. C: ES. D: SE.

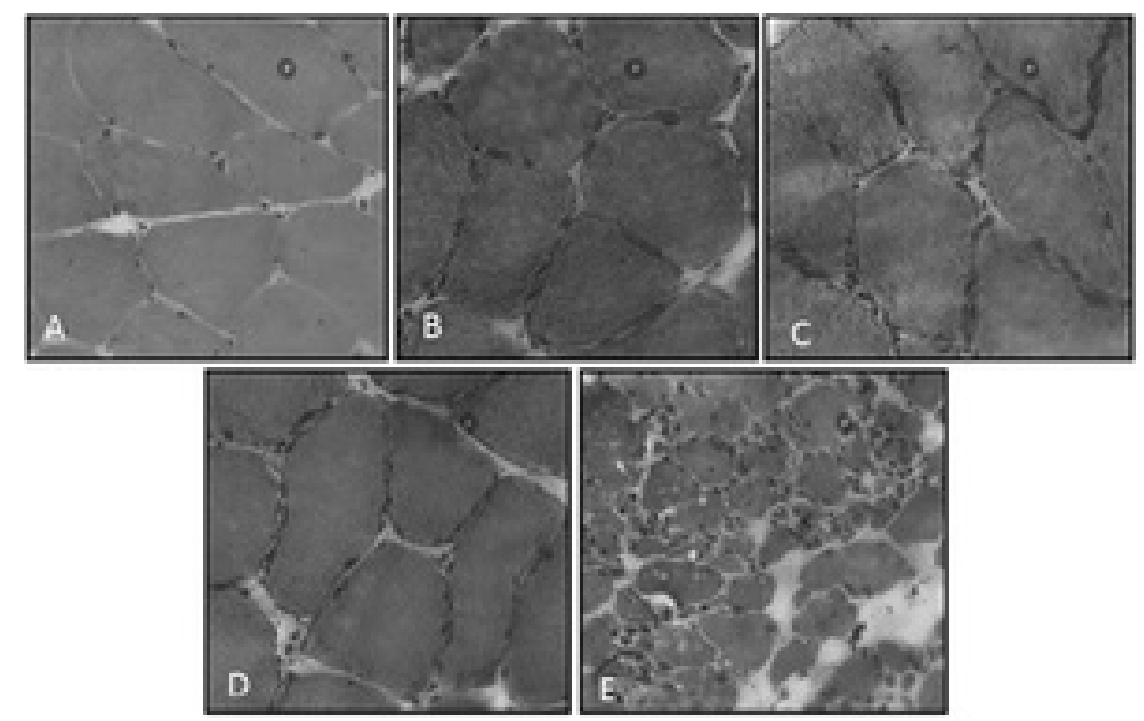

Figure 3 - Tibial cranial muscle analysis of the control group (A), EE (B), ES (C), SE (D) and denervated group (E).

\section{- Discussion}

All nerves can be used as a potential donor nerve since Viterbo et al. ${ }^{2}$ introduced the ES and SE neurorrhaphy without donor nerve injury. However, many authors doubted wether this nerve repair could substitute completely the traditional end-to-end neurorrhaphy and keep saying that this is the best method to use in nerve repair ${ }^{18,19,22}$. The present study compared the efficiency of three different techniques of neurrorhaphy: 
the end-to-end, end-to-side and side-to-end. The most important result was that all three methods retained the nerve and muscle function without difference in quality and time recovery. Unlike these findings, Liao et al. ${ }^{18}$ and Jaeger et $a . .^{22}$ found superior results regarding the time and quality of recovery for the group with end-to-end neurorrhaphy. However, we could observe that the the research conducted comparing the end-to-end and end-to-side neurorrhaphy used different donor nerves, which causes an important bias in the research and makes it difficult to compare with our findings, since we were careful to marter the same nerve as a donor in all techniques ${ }^{18,19,22}$.

The axonal sprouting of end-to-side neurrorhaphy is not completely known. It remains a research subject. The macrophages related to the Wallerian degeneration seem to be responsible for the perineurium absorption, that allows neurotrophins of the recipient nerve to stimulates the axonal sprouting ${ }^{23-25}$.

Concerning the assessment of the cranial tibial muscle mass in this study, there was no statistically significant difference in the EE, ES and SE groups, which can possibly be explained by an equal reinnervation in the groups. Trumble ${ }^{26}$ demonstrated that the partial mass loss of the muscle is correlated with the muscle denervation grade. Besides, there was no statistically significant difference in the initial and final body mass of the rats between groups. These results confirm the results found at the cranial tibial measurement.

A $10 \mathrm{~mm}$ nerve graft was used with the aim to extend the peroneal nerve to provide an ES and SE neurorraphy without tension. This length also enables a proper introduction of the free neural end into the muscle, preventing spontaneous regeneration. Thereby, the objective was not to repair the nerve gap. The obsevation time of six months aimed at the full recovery both nerve and muscle functions, and also brain neuroplasticity, since the animals march was assessed. We know the robust nature of neural regeneration in the rodent hindlimb, which could be a potential issue with a short nerve graft and a long period of study. However, this great potential of neural regeneration was similar in all groups, and no statistically significant differences were found between groups. Then, the high potential of neural regeneration did not interfere in the analysis.

In the literature, ES is mainly reported as an alternative technique in the worst cases of nerve injuries with no proximal nerve end and the impossibility to perform EE. This selection bias increases the chance of poor results. The present study demonstrated similar outcomes in EE and ES. The authors consider the findings of this study very important. Therefore, ES can be used not as a substitute but as an alternative to EE in neurorrhaphy situations. The authors recommend more experimental studies to a better understanding of the intriguing phenomenon of ES.

The results of this experimental study demonstrate that there are no functional or histological differences between these different types of neurorrhaphy. Moreover, ES and SE can be safely used for the same indications of EE with a lower morbidity, especially when the proximal end is not available.

From all evaluation methods used at this study, we considered the functional peroneal index the most significant one because it demonstrates all regeneration process, from the axonal reinervation and muscular regeneration to the walking results, and at this method the three experimental groups were similar and also equal to the control group after 90 and 180 days.

\section{- Conclusion}

The experimental model used demonstrated that there were no functional 
or histological differences in the end-to-side, side-to-end and end-to-end techniques of neurrorhaphy.

\section{References}

1. Harris ME, Tindall SC. Techniques of peripheral nerve repair. Neurosurg Clin N Am. 1991 Jan;2(1):93-104. PMID: 1821737.

2. Viterbo F, Trindade JC, Hoshino K, Mazzoni Neto A. Latero-terminal neurorraphy without removal of the epineural sheath: Experimental study in rats. Rev Paul Med. 1992 Nov-Dec;110(6):267-75. PMID: 1341024.

3. Viterbo F, Trindade JC, Hoshino K, Mazzoni Neto A. End-to-side neurorraphy with removal of the epineurial sheath: An experimental study in rats. Plast Reconstr Surg. 1994 Dec;94(7):1038-47. PMID: 7972457.

4. Viterbo F, Trindade JC, Hoshino K, Mazzoni A. Two end-to side neurorraphies and nerve graft with removal of the epineural sheath: experimental study in rats. Br J Plast Surg. 1994 Mar;47(2):75-80. PMID: 8149062.

5. Viterbo F, Teixeira E, Hoshino K, Padovani CR. End-to-side neurorraphy with and without perineurium. Sao Paulo Med J. 1998 SepOct;116(5):1808-14. PMID: 10030106.

6. Ballance CA, Ballance HA, Stewart P. Remarks on the operative treatment of chronic facial palsy of peripheral origin. Br Med J. 1903 May 2;1(2209):1009-13. PMID: 20760866.

7. Ballance CA. Some results of nerve anastomosis. Br J Surg. 1923;11:327-46. doi: 10.1002/bjs.1800114211.

8. Stookey B. Artificial nerve branches for innervation of paralyzed muscles. Arch Surg. 1923;6:731-8. doi: 10.1001/ archsurg.1923.01110190072002.

9. Sherren J. Remarks on some points in the treatment of nerve injuries. Br Med J. 1910 Jan 15;1(2559):130-1. PMID: 20764858.

10.Yamamoto Y, Sasaki S, Sekido M, Yokoyama T, Tsutsumida A, Furukawa $H$, Sawamura $Y$, Sugihara T. Alternative approach using the combined technique of nerve crossover and cross-nerve grafting for reanimation of facial palsy. Microsurgery. 2003;23(3):2516. doi: 10.1002/micr.10115.

11.Kumar PA, Hassan KM. Cross-face nerve graft with free-muscle transfer for reanimation of the paralysed face: a comparative study of the single stage and two-stage procedures. Plast Reconstr Surg. 2002 Feb;109(2):45162. PMID: 11818819.

12.Viterbo F, Franciosi LF, Palhares A. Nerve graftings and end-to-side neurorrhaphies connecting the phrenic nerve to the brachial plexus. Plast Reconstr Surg. 1995 Aug;96(2):494-5. PMID: 7624435.

13.Galli SK, Valauri F, Komisar A. Facial reanimation by cross-facial nerve grafting: Report of five cases. Ear Nose Throat J. 2002 Jan;81(1):25-9. PMID: 11816384.

14.Koh KS, Kim JK, Kim CJ, Kwun BD, Kim SY. Hypoglossal-facial crossover in facialnerve palsy: Pure end-to-side anastomosis technique. Br J Plast Surg. 2002 Jan;55(1):2531. doi:10.1054/bjps.2001.3727.

15. Yoleri L, Songur E, Yoleri O, Vural T, Cagdas A. Reanimation of early facial paralysis with hypoglossal/facial end-to-side neurorrhaphy: a new approach. J Reconst Microsurg. 2000 Jul;16(5):347-55. PMID: 10954315.

16.Dubovy P, Raška O, Klusáková I, Stejskal I, Celakovsky P, Haninec P. Ciliary neurotrophic factor promotes motor reinnervation of the musculocutaneous nerve in an experimental model of end-to-side neurorrhaphy. BMC Neurosci. 2011 Jun 22;12:58. PMID: 21696588.

17.Lykissas MG, Korompilias AV, Batistatou AK, Mitsionis GI, Beris AE. Can end-to-side neurorrhaphy bridge large defects? An experimental study in rats. Muscle Nerve. 2007 Nov;36(5):664-71. PMID: 17661375.

18.Liao WC, Chen JR, Wang YJ, Tseng GF. The efficacy of end-to-end and end-to-side nerve repair (neurorrhaphy) in the rat brachial plexus. J Anat. 2009 Nov;215(5):506-21. PMID: 19682138.

19.Spyropoulou GA, Lykoudis EG, Batistatou A, Papalois AE, Tagaris G, Pikoulis E, Bastounis $E$, Papadopoulos $O$. New pure motor nerve experimental model for the comparative study between end-to-end and end-toside neurorrhaphy in free muscle flap neurotization. J Reconstr Microsurg. 2007 Oct;23(7):391-8. PMID: 17975766.

20.Medinaceli L, Freed W, Wyatt RJ. An index of the functional condition of rat sciatic nerve based on measurements made from walking 
tracks. Exp Neurol. 1982 Sep;77(3):634-43. PMID: 7117467.

21.Bain JR, Mackinnon SE, Hunter DA. Functional evaluation of complete sciatic, peroneal, and posterior tibial nerve lesions in the rat. Plast Reconstr Surg. 1989 Jan;83(1):129-38. PMID: 2909054.

22.Jaeger MR, Braga-Silva J, Gehlen D, PereiraFilho Gde A, Zettler CG, de Souza MA, Veas $J R$, Sebben A. End-to-End versus end-toside motor and sensory neurorrhaphy in the repair of the acute muscle denervation. Ann Plast Surg. 2011 Oct;67(4):391-6. PMID: 21587041.

23.Akeda $\mathrm{K}$, Hirata $\mathrm{H}$, Matsumoto $\mathrm{M}$, Fukuda A, Tsuji M, Nagakura T, Yoshida SOT, Uchida A. Regenerating axons emerge far proximal to the coaptation site in end-to-side nerve coaptation without a perineurial window using a T-Sharped chamber. Plast Reconstr Surg. 2006 Apr;117(4):1194-203. PMID: 16582786.

24. Matsumoto $M$, Hirata $H$, Nishiyama M. Schwann cells can induce collateral sprouting from intact axons: experimental study of end-to-side neurorrhaphy using a Y-chamber model. J Reconstr Microsurg. 1999 May;15(4):281-6. PMID: 10363551.

25.Beris A, Lykissas M, Korompilias A, Mitsionis G. End-to-side nerve repair in peripheral nerve injury.J Neurotrauma. 2007;24(5):90916. doi: $10.1089 /$ neu.2006.0165

26.Trumble TE. Peripheral Nerve Transplantation: The effects of predegenerated grafts and immunosuppression. J Neural Transplant Plast. 1992 Jan-Mar;3(1):39-49. PMID: 1571398.

\section{Correspondence:}

Fausto Viterbo

Rua Domingos Minicucci Filho, 587

18607-030 Botucatu - SP Brasil

Tel.: (55 14)3882-5414

fv@faustoviterbo.com.br

Received: May 21, 2017

Review: July 24, 2017

Accepted: Aug 28, 2017
Conflict of interest: none

Financial source: none
${ }^{1}$ Research performed at Department of Plastic Surgery, Orthopedy and Surgery Laboratory, Universidade Estadual Paulista (UNESP), Botucatu-SP, Brazil. 